\title{
Supplementary of
}

\section{Retrieval of Gridded Aerosol Direct Radiative Forcing Based on Multi-platform Datasets}

Yanyu Wang ${ }^{1}$, Rui Lyu ${ }^{1}$, Xin Xie ${ }^{1}$, Meijin Huang ${ }^{2}$, Junshi Wu ${ }^{3}$, Haizhen $\mathrm{Mu}^{3}$, Qiu-Run $5 \mathrm{Yu}^{4}$, Qianshan $\mathrm{He}^{3,5^{*}}$, Tiantao Cheng ${ }^{6,7 *}$

${ }^{1}$ Shanghai Key Laboratory of Atmospheric Particle Pollution and Prevention (LAP ${ }^{3}$ ), Department of Environmental Science and Engineering, Institute of Atmospheric Sciences, Fudan University, Shanghai, 200438, China

${ }^{2}$ Fujian Meteorological Observatory, Fuzhou, 350001, China

$10{ }^{3}$ Shanghai Meteorological Service, Shanghai, 200030, China

${ }^{4}$ Key Laboratory of Meteorological Disaster, Ministry of Education (KLME)/Joint International Research Laboratory of Climate and Environment Change (ILCEC), Nanjing University of Information Science and Technology, Nanjing, 210044, China

${ }^{5}$ Shanghai Key Laboratory of Meteorology and Health, Shanghai, 200030, China.

$15{ }^{6}$ Department of Atmospheric and Oceanic Sciences, Institute of Atmospheric Sciences, Fudan University, Shanghai, 200438, China

${ }^{7}$ Shanghai Institute of Eco-Chongming (SIEC), Shanghai, 200062, China

Correspondence to: Qianshan He (oxeye75@163.com); Tiantao Cheng(ttcheng@ fudan.edu.cn). 
20 This Supplementary Information (SI) includes 3 figures.

\section{Supplementary Figures:}

Figure S1. The boxplot of MERRA-2 SSA and sunphotometer in Pudong, Taihu, and Xuzhou.

Figure S2. $48 \mathrm{~h}$ backward trajectories of air mass by HYSPLIT 4, which are terminating at Fuzhou at $500 \mathrm{~m}$ altitude level.

25 Figure S3. $48 \mathrm{~h}$ backward trajectories of air mass arriving at Yong'an at $500 \mathrm{~m}$ altitude level and calculated every $24 \mathrm{~h}$ from October 22 to October 24, 2015. 


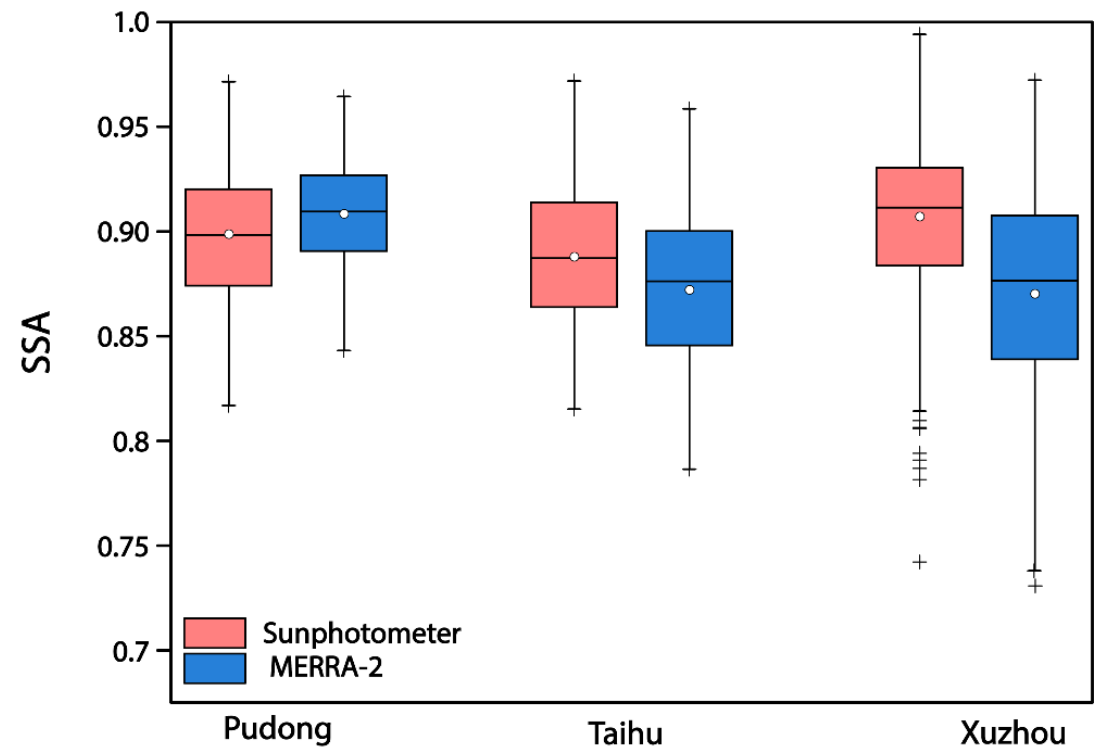

Figure S1. The boxplot of MERRA-2 SSA and sunphotometer in Pudong, Taihu, and Xuzhou. The central marks in each box are the median value while the lower and upper edges of the boxes indicate 25th and 75th percentiles. The whiskers show extreme values and the outliers are maked with "+". 


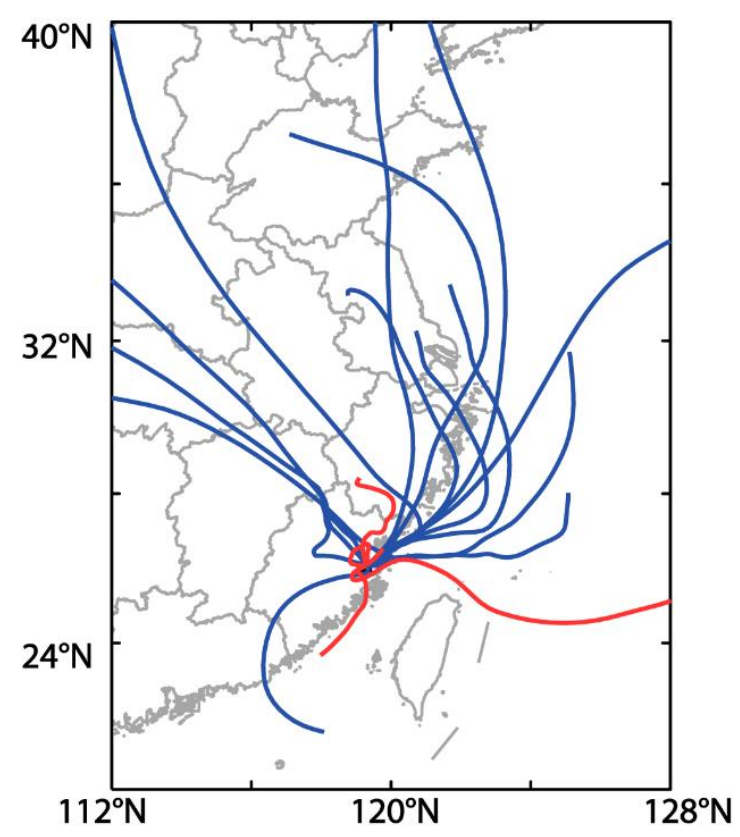

Figure S2. $48 \mathrm{~h}$ backward trajectories of air mass by HYSPLIT 4, which are terminating at Fuzhou at $500 \mathrm{~m}$ altitude level. Blue lines are the trajectories with negative relative error and the red lines are the tragectories with positive relative error. 
NOAA HYSPLIT MODEL

Backward trajectories ending at 0200 UTC 24 Oct 15

GDAS Meteorological Data

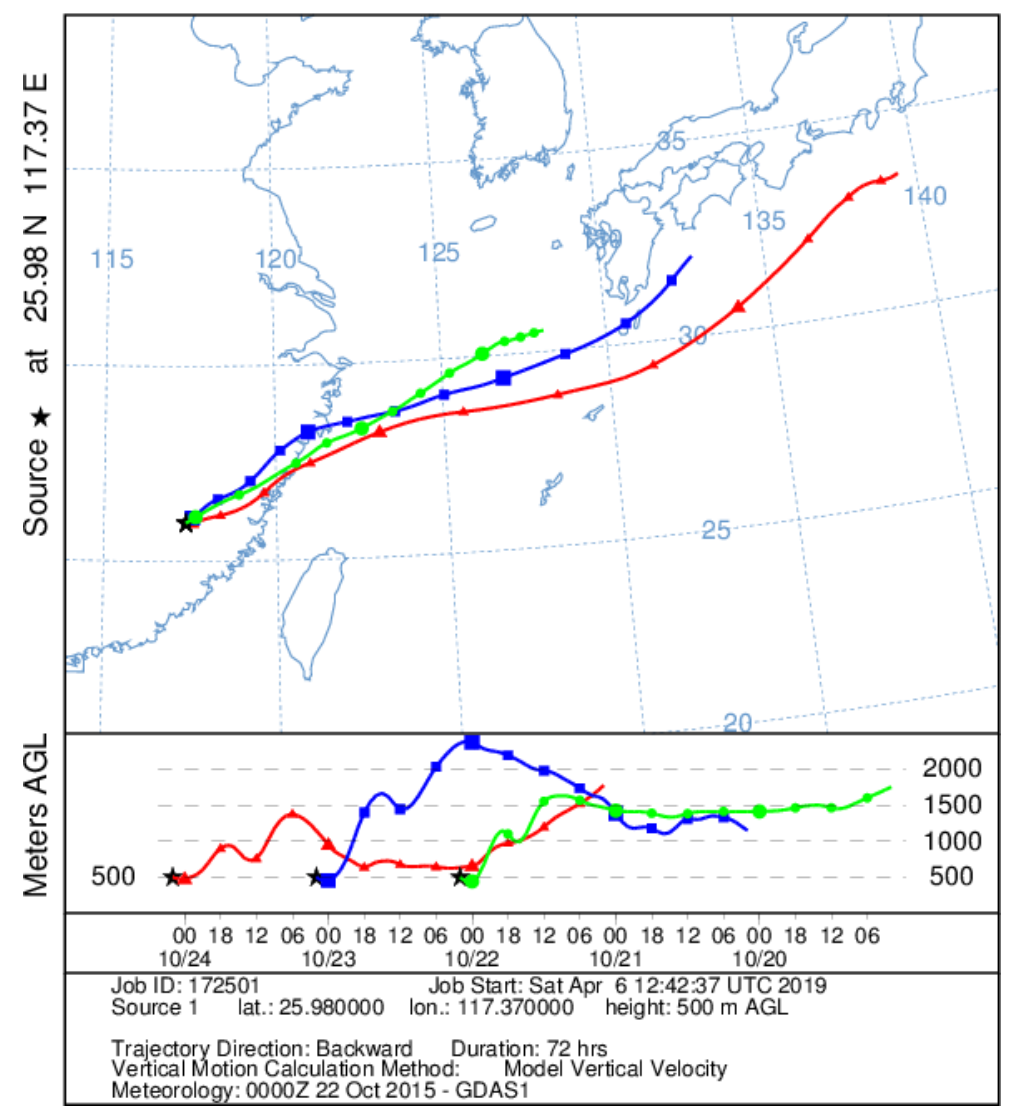

Figure S3. $48 \mathrm{~h}$ backward trajectories of air mass arriving at Yong'an at $500 \mathrm{~m}$ altitude level and calculated every $24 \mathrm{~h}$ from October 22 to October 24, 2015. The start time is 2:00 (UTC) during satellite passing by. 